
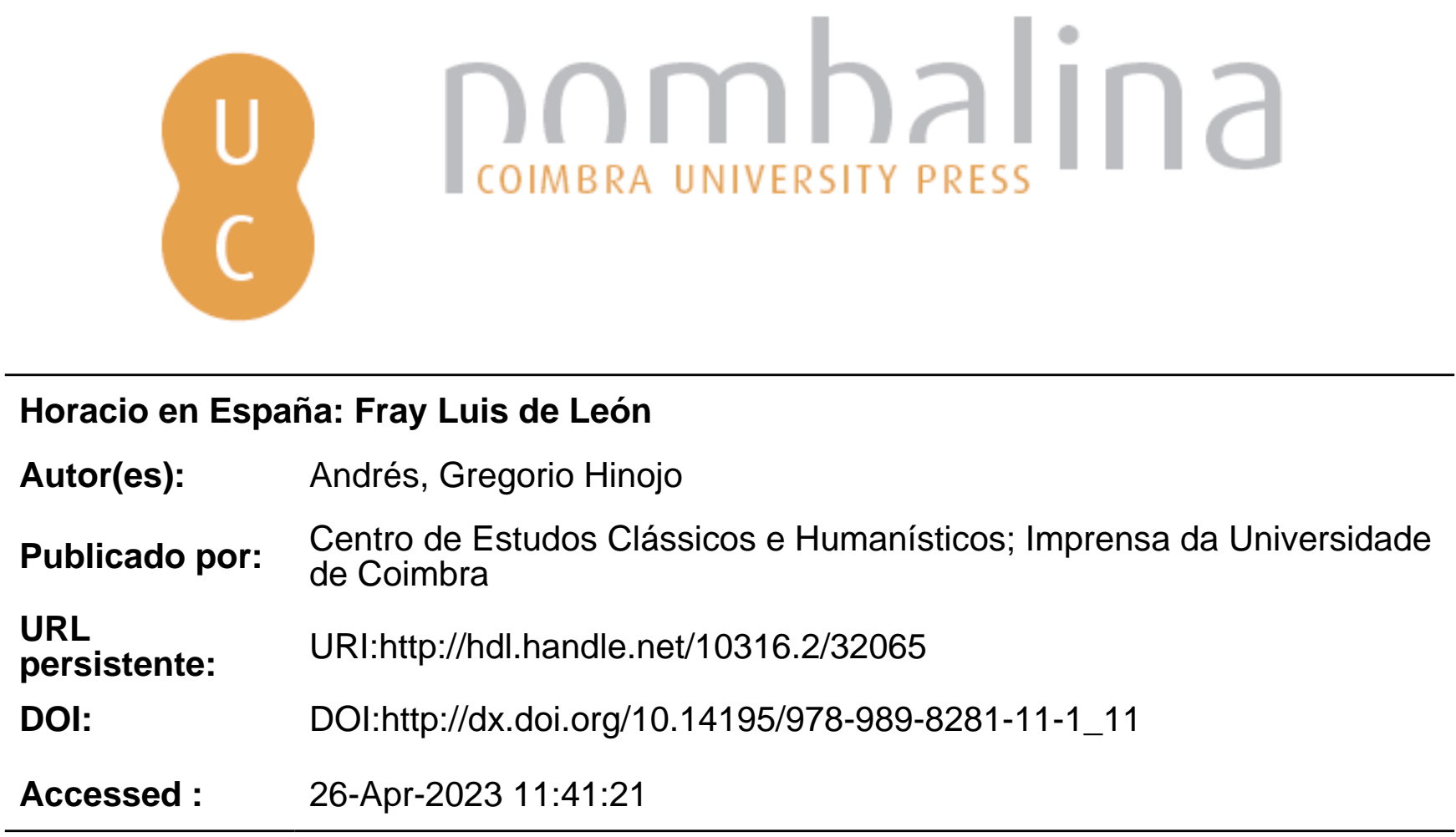

A navegação consulta e descarregamento dos títulos inseridos nas Bibliotecas Digitais UC Digitalis, UC Pombalina e UC Impactum, pressupõem a aceitação plena e sem reservas dos Termos e Condições de Uso destas Bibliotecas Digitais, disponíveis em https://digitalis.uc.pt/pt-pt/termos.

Conforme exposto nos referidos Termos e Condições de Uso, o descarregamento de títulos de acesso restrito requer uma licença válida de autorização devendo o utilizador aceder ao(s) documento(s) a partir de um endereço de IP da instituição detentora da supramencionada licença.

Ao utilizador é apenas permitido o descarregamento para uso pessoal, pelo que o emprego do(s) título(s) descarregado(s) para outro fim, designadamente comercial, carece de autorização do respetivo autor ou editor da obra.

Na medida em que todas as obras da UC Digitalis se encontram protegidas pelo Código do Direito de Autor e Direitos Conexos e demais legislação aplicável, toda a cópia, parcial ou total, deste documento, nos casos em que é legalmente admitida, deverá conter ou fazer-se acompanhar por este aviso.

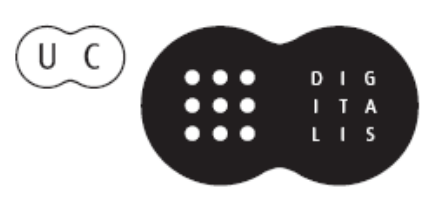




\section{Horácio \\ e a sua \\ Perenidade}

\section{Maria Helena Rocha Pereira, José Ribeiro Ferreira e Francisco de Oliveira}

IMPRENSA DA UNIVERSIDADE DE COIMBRA 


\title{
Horacio en España: Fray Luis de León
}

\author{
Gregorio Hinojo Andrés \\ Universidad de Salamanca
}

Tenho pena de não poder pronunciar a minha palestra na língua de Camões, tão próxima em muitos aspectos da castelhana, e tão diferente noutros, sobretudo na fonética, muito mais rica e variada do que a de Cervantes. Dizia o Brocense, grande tradutor de Horácio e colega no Studium Salmanticense de Frei Luís de Leão (para além de ser natural da Extremadura espanhola e de ter estudado em Portugal com um seu tio): Latine loqui corrumpit ipsam latinitatem, que pode ser traduzido do seguinte modo: "Falar mal uma língua destrói e corrompe a sua beleza e a sua identidade”. É por isso que renuncio a destruir uma língua tão sonora e de uma fonética tão eufónica. Peço-lhes, pois, muitas desculpas e tentarei falar e ler devagar e com claridade para que todos os presentes me possam compreender. Muito obrigado por ter sido convidado para dissertar nesta velha Universidade sobre dois dos meus poetas preferidos e que com os anos se me tornam muito mais atractivos, tanto pela sua perfeição formal como pelos seus postulados poéticos e literários. E é agora que começo a minha palestra...

\author{
me Colchus et qui dissimulat metum \\ Marsae cohortis Dacus et ultimi \\ noscent Geloni, me peritus \\ discet Hiber Rhodanique potor (Carm. II, 20).
}

Me conocerán el colco, y el dacio

que oculta su miedo a la cohorte marsa,

y los remotos gelonos; me aprenderá

el culto ibero y el que bebe del Ródano.

Con estos versos clausuraba Horacio su segundo libro de las Odas, de los carmina, y con su vanidad no reñida con su sobriedad epicúrea proclamaba su fe en la inmortalidad literaria y su seguridad de que el turco, el rumano, el remoto ruso, el francés y el docto ibero lo iban a conocer y a leer; su presencia esta mañana en los extremos del occidente europeo le agradaría inmensamente y confirma la clarividencia de su profecía; sin duda, non omnis mortuus est.

Resulta en numerosas ocasiones muy difícil precisar con exactitud el alcance de la influencia y de la presencia de determinados autores clásicos en los escritores de nuestras culturas, ya que muchos de los temas y de los argumentos de las grandes figuras de la tradición antigua se han convertido en lugares comunes o pertenecen ya al patrimonio cultural y literario universal. En el caso de Horacio las dificultades se incrementan de forma singular, debido a la peculiaridad del poeta, a su reconocido clasicismo y a la enorme variedad 
de ideas y actitudes que su poesía encierra. Es un poeta esquivo y astuto al que resulta punto menos que imposible encajar en un solo sistema filosófico. La crítica ha querido ver en él sucesiva (y a veces simultáneamente) un estoico, un epicúreo, un cínico, y hasta un cristiano ${ }^{1}$. Además debe destacarse la riqueza y diversidad de la lírica horaciana: poesía religiosa y heroica, moral, satírica, rústica y campestre, amorosa, filosófica, política, de banquetes, himnos, odas literarias, etc.; de forma que puede afirmarse que en el venusino se preludian ya casi todos los temas de la poesía posterior. Pero el poeta no es sólo rico y variado en su temática, sino que es versátil en su acercamiento y en su actitud poética; así puede pasar de una postura satírica y pesimista, a una cruel y descarnada sin renunciar a la dulzura y placeres de la buena mesa y de la vida sosegada. Por ello la coincidencia temática e incluso de tratamiento, no es siempre indicio de imitación o de pervivencia.

Por otra parte, en los últimos siglos de la Edad Media y durante el Renacimiento hay una superproducción de Antologías, Polianteas, Florilegios, repertorios de frases y de pasajes destacados de autores antiguos, y resulta complicado y muy arriesgado decidir qué se debe al conocimiento de estos compendios y qué a la lectura y manejo de los escritores clásicos. La presencia de un tema, de un tópico literario, de una cita, de un recurso poético de un autor clásico no supone necesariamente el conocimiento directo o la lectura del original; en muchas ocasiones estos elementos proceden de fuentes intermedias o de las citadas antologías y colecciones.

Con estas precisiones sólo he querido poner coto y freno a los que buscan pervivencia y presencia de Horacio en numerosos poetas. No creemos ni útil ni necesario, además de que sería largo y tedioso, enumerar las traducciones de Horacio en nuestro Siglo de Oro ni mucho menos todos los autores que de una forma u otra imitan o beben en las fuentes del venusino ${ }^{2}$. Nuestra disquisición filológica, más que revisar y exponer todas las influencias horacianas, pretende determinar el momento culminante de su difusión y de su supervivencia literaria, que sin duda, se alcanza con fray Luis.

\section{Horacio en la Edad Media}

Hay un consenso generalizado entre los estudiosos sobre la escasa difusión de Horacio en la actividad literaria y cultural del Medievo hispánico, fenómeno que no sólo es exclusivo de la península. Esta escasa difusión del venusino contrasta con la popularidad e influencia de las que gozaron Virgilio y Ovidio, éste último casi más que el autor de la Eneida; contrasta también con el prestigio y fortuna que alcanzó en los Siglos de Oro (XVI y XVII), como ya destacó acertadamente D. Marcelino Menéndez y Pelayo.

\footnotetext{
${ }^{1}$ Ettinghausen, H. "Horacianismo vs. neoestoicismo en la poesía de fray Luis de León”, Fray Luis de León: Historia, humanismo y letras, Salamanca 1996, p. 242.

${ }^{2}$ Los interesados pueden consultar la monografía de D. Marcelino Menéndez y las obras que he adjuntado en la bibliografía, algunas de ellas verdadero repertorio de temas y de imitaciones horacianas, como la de Vicente Cristóbal.
} 
En efecto, mientras que en su densa y documentada obra dedica tres gruesos volúmenes a la presencia de Horacio en el Renacimiento, a la medieval apenas una, que resume así: "No con traducciones, sino con imitaciones, empezó a manifestarse entre nosotros la influencia horaciana, al revés de lo que aconteció con otros autores clásicos. Horacio fue de los poetas latinos menos saboreados en la Edad Media, y hasta muy entrado el siglo XV apenas encontramos reminiscencias de sus ideas y estilo. Ofrécenos una muy notable el esclarecido Marqués de Santillana, que debió conocer ya, aunque en no muy correctos originales, las obras del lírico latino. Demuéstranlo las estancias XVI, XVII y XVIII de la Comedieta de Ponza, en las cuales felizmente parafrasea el Beatus

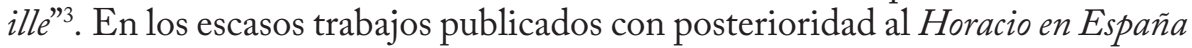
se han confirmado estas opiniones de D. Marcelino, entre ellos en uno, bien documentado, de Tomás González Rolán ${ }^{4}$. Así, con motivo del bimilenario del nacimiento de Horacio, celebrado en 1935, el Padre F. Rubio ${ }^{5}$ publicó un trabajo sobre los fondos horacianos de la biblioteca de E1 Escorial en el que, después de comprobar que ninguno de los manuscritos que allí se encontraban era de origen español, afirmaba que "Horacio es uno de los clásicos de los que no se tuvo noticia en España durante la Edad Media".

La tesis de que las estancias citadas de la Comedieta de Ponza son una paráfrasis del Beatus ille y de que con esta obra empieza todo estudio horaciano en la Península, ha sido asumida, aunque con algunas matizaciones, entre otros por Rafael Lapesa, Elías E. Rivers, Gareth A. Davies, Arnold G. Reincherberger, Miguel Garci-Gómez y María Rosa Lida ${ }^{6}$.

Según esto, el desinterés o interés por Horacio serviría para caracterizar dos periodos de nuestra historia, el medieval y el renacentista; nuestro Juan de Mena, por su falta de atención a Horacio sería prototipo de la cultura medieval, el Marqués de Santillana podría ser considerado como prerrenacentista.

Con todo, hay autores, como María-Bárbara Quint, que defienden la presencia y el influjo de Horacio en el Medievo, al menos con sus Sátiras, Epistolas y Ars poetica, hasta tal punto que se le conoció casi exclusivamente como satiricus.

Para explicar esta ausencia del Horacio lírico se han buscado distintas causas o interpretaciones. Ya D. Marcelino ${ }^{7}$, tras destacar su escasa presencia, nos dice: "Y era natural que así sucediese, aparte de otras consideraciones obvias, porque es la forma lírica la menos susceptible de ser disfrutada y apreciada debidamente en tiempos de no refinada cultura estética, aunque de ciencia profunda e inspiración valiente, cuales fueron los tiempos medios. La poesía narrativa halaga todas las imaginaciones; mas para sentir y aquilatar

${ }^{3}$ Menéndez Pelayo, M., Horacio en España, Madrid 1985 (recogido en su Bibliografía hispano-latina clásica, Santander 1951, VI), p. 40.

${ }^{4}$ González Rolán, T., "Horacio en el Medievo hispánico", Horacio, el poeta y el hombre, Santiago de Compostela 1994, p. 147.

${ }^{5}$ Rubio, F., "Los fondos horacianos de la Biblioteca del Escorial", La Ciudad de Dios 152, 1936, p. 389.

${ }^{6}$ Citados por González Rolán, T., op. cit., p. 147.

${ }^{7}$ Menéndez Pelayo, M., op. cit., p. 290. 
los primores de la oda o de la sátira al modo clásico requiérese una educación humanística que sólo desde el Renacimiento acá han logrado los pueblos de Europa. Ni el fondo de Horacio ni su expresión convenían a la Edad Media, y si, por maravilla, encontramos algún lejanísimo rastro, más en los latinistas eclesiásticos que en los poetas de lenguas vulgares, nunca es una verdadera y directa imitación, reduciéndose estos vestigios, unas veces a ciertas formas rítmicas conservadas por la tradición de los himnos de la Iglesia, y, otras, a coincidencias, que pudieran ser casuales, en pensamientos comune". Igualmente María Rosa Lida ${ }^{8}$ piensa que el que Horacio sobre todo el lírico sea una figura secundaria respecto a Virgilio y Ovidio se debe a que el principal mérito de Horacio es su forma exquisita, su pura forma, aunque no se perciba el ritmo delicado del verso o la arquitectura de la narración en un episodio de la Eneida; aunque se pierda el juego malicioso de las Heroidas o el encadenamiento como de sueño de las Metamorfosis, queda siempre el residuo sólido de una apasionada anécdota; pero si se deja de percibir la forma de composiciones que huyen de la anécdota y del argumento, si cesa la comprensión de su métrica, Horacio, Romanae fidicen lyrae, se convierte en el 'Orazio satiro' de la Divina Comedia".

Una segunda explicación puede ser el deseo e interés de utilizar los textos clásicos como medio o instrumento para explicar o interpretar los textos sagrados; la filología, lo mismo que la philosophia, eran ancillae theologiae y los poemas líricos horacianos no se prestaban a esta finalidad.

Una última causa de la escasa presencia del Horacio lírico en el medievo puede ser su fama de poeta inmoral, licencioso y cantor de las pasiones y de los amores impúdicos. Así en unos versos de Nokter Balbulus se lo define como lubricus et vagus:

Vt cecinit sensu verax Horatius isto cetera vitandus lubricus atque vagus pallida mors aequo pulsans pede sive tabernas aut regum turres 'Vivite' ait'venio'.

El carácter deshonesto e impúdico de su poesía lírica pervivió incluso en el Renacimiento y se aconsejaba la selección de sus poemas para evitar los inmorales.

Concluimos con la idea de que el Horacio lírico fue muy poco conocido en la Edad Media y de que la presencia en el Marquès de Santillana puede deberse a un texto de un Florilegio o una Antología, como defiende y demuestra con acierto, el Profesor Lapesa9.

\section{Horacio en el Renacimiento}

Frente a la escasa presencia de Horacio en la Edad Media, en el Renacimiento va a convertirse en el poeta latino más valorado y más imitado,

\footnotetext{
${ }^{8}$ Lida, M. R., La tradición clásica en España, Barcelona, 1975 (esp. p. 255 y ss.).

${ }^{9}$ Lapesa, R., La obra literaria del Marqués de Santillana, Madrid 1957, p. 146.
} 
y será precisamente con fray Luis de León con quien consiga el máximo esplendor de su influencia. Como acertadamente se ha señalado ${ }^{10}$, ninguno de nuestros hombres de letras es más digno y merecedor de identificarse con el peritus Hiber de la oda que hemos citado al principio de esta intervención.

$\mathrm{Su}$ acercamiento a Horacio va a producirse de forma escalonada, iniciándose con la traducción de un número significativo de odas (veinticuatro y un epodo), traducidas con bastante libertad y adaptándolas a los versos castellanos - incluso, en ocasiones, realiza dos versiones -; de las traducciones más o menos libres pasa a la recreación de alguna de ellas para concluir con la poesía original que está cargada de reminiscencias y alusiones a los poemas del venusino. Ya Menéndez Pelayo descubrió más de doscientos pasajes horacianos en la poesía original luisiana, número que podría incrementarse con los medios informáticos modernos. Solo en el primer poema, ¡Qué descansada vida..., reseña J. F. Alcina ${ }^{11}$ veinte textos horacianos como fuente o inspiración del poeta.

Coincidimos plenamente con Alberto Blecua ${ }^{12}$ cuando afirma que los primeros ejemplos conocidos de traducciones castellanas de odas no fragmentarias de Horacio se deben a fray Luis, ya que la Ode ad florem Gnidi de Garcilaso, aunque es la primera composición lírica verdaderamente de tono clásico, no es una traducción. Fundamenta su afirmación el Profesor Blecua en que los breves fragmentos de odas traducidos por Mal Lara en su Philosophia vulgar no muestran síntomas e influjos de traducciones anteriores, pero especialmente se apoya en el testimonio del Brocense, testimonio que, como Blecua advierte, no admite dudas.

En 1574, hallándose fray Luis en las cárceles del Santo Oficio, publicó el Brocense sus Anotaciones a Garcilaso, insertando en ellas las traducciones de las odas 22 del libro I, 10 del II, 13 del IV, y el epodo segundo de Horacio, poniendo en la primera la advertencia siguiente: "Trató esto elegantemente Horacio. Y porque un docto de estos reinos la tradujo bien, y hay pocas cosas de éstas en nuestra lengua, la pondré aquí toda, y ansí entiendo hacer en el discurso de estas Anotaciones"13. Calló, sin duda, el nombre del intérprete, por no atizar el odio de sus perseguidores.

Se completa el testimonio del Brocense con un elogio de la traducción y del metro elegido para el célebre Beatus ille: "La cual por estar bien trasladada del autor de las pasadas, y por ser nueva manera de verso y muy conforme con el latino, no pude dejar de ponerla aquî" ${ }^{14}$. La traducción comienza:

Dichoso el que de pleitos alejado

cual los del tiempo antigo

${ }^{10}$ Cristóbal, V., "Horacio y fray Luis", Horacio, el poeta y el hombre, Santiago 1994, p. 163.

${ }^{11}$ Alcina, J. F., Fray Luis de león. Poesía, Madrid 1989, pp. 69-75.

12 Blecua Perdices, A. "El entorno poético de fray Luis", Academia Literaria Renacentista. I Fray Luis, Salamanca, 1981, p. 91.

${ }_{13}^{13}$ Gallego Morell, A., Gracilazo de la Vega y sus comentaristas, Madrid 1972, p. 266.

14 Ibid., op, cit., p. 286; citado por A. Blecua, cuyo subrayado mantengo. 
labra sus heredades no obligado al logrero enemigo.

Se trata de una estrofa de cuatro versos, dos endecasílabos y dos heptasílabos con rima consonante alterna. Antes de seguir adelante, queremos advertir que la mayoría de los críticos hablan de las "cuatro odas" introducidas por el Brocense, pero en realidad se trata de tres odas y un epodo, el II, el del Beatus ille; el propio fray Luis es consciente de ello y ha traducido con metros diferentes las odas y el epodo, como no podía ser menos en alguien que quiere ser buen traductor, ya que en Horacio hay plena distinción entre odas y epodos, tanto por los temas como por los metros. Se trata de una confusión que se introdujo en su día y los editores y críticos siguen repitiendo sin reflexionar.

Los comentarios del Brocense tuvieron una enorme éxito y una difusión extraordinaria, especialmente porque provocaron una encendida polémica en torno a la imitación y fueron por ello un escaparate y un instrumento eficaz de difusión de las odas de fray Luis y del ulterior desarrollo de la lírica horaciana. Suscitaron además una emulación en la escuela sevillana; y en las Anotaciones de Herrera a Garcilaso se introducen también unas traducciones de Horacio, realizadas, una por el propio Herrera y otra por Girón, para rivalizar con las del maestro salmantino, ya que se escriben en los mismos metros, aunque en verso libre y se repite la del Beatus ille, la que había merecido más elogios por parte del Brocense. Desde ese momento se multiplican las traducciones e imitaciones de las odas, con rivalidad y emulación como los clásicos exigen. Puede afirmarse, como conclusión, que en torno a fray Luis y Salamanca - el Brocense, Almeida, Espinosa, Francisco de la Torre - se gestan, antes de 1572, las primeras traducciones de las odas de Horacio. Si no fue fray Luis el iniciador del género, que todo parece indicar que sí, a lo menos fueron sus traducciones incluidas en la edición de Garcilaso las que comenzaron una moda que, a causa de la controversia herreriana, tuvo más adeptos entre los poetas andaluces. Pueden verse en las obras de Francisco de la Torre y en la primera parte de Fore. Este sería el inicio de un horacianismo consciente y plenamente adoptado en la poesía española. Si numerosa, son las traducciones de Salamanca, como las de Francisco Sánchez, D. Juan de Almeida, D. Alonso de Espinosa, no desmerecen las de Sevilla, como las de Francisco de Medina, Diego Girón, Fernando de Herrera, Francisco de Medrano y otras, además de la de los Argensola, Gutierre de Cetina, Meléndez Valdés y Hernan de Acuña.

Antes de concluir este apartado, me parece muy pertinente destacar la importancia que fray Luis concedió a las traducciones, ya que el número de versos traducidos son más del doble de los originales. "Ello permite como acertadamente afirma Lázaro Carreter ${ }^{15}$ - suponer que no se trató de

\footnotetext{
${ }^{15}$ Lázaro Carreter, F., "Fray Luis de León y la clasicidad”, Fray Luis de León: Historia, humanismo y letras, Salamanca 1996, p. 19.
} 
una actividad secundaria, y a la que no hemos concedido los críticos toda la atención que merece. Entre otras cosas, porque, al vencer las dificultades de la traducción, estaba forjándose su propia lengua poética”.

\section{IMITACIÓN DE HORACio}

Hoy nadie duda de que Horacio fue uno de los modelos - el más importante, en mi opinión -, de la poesía de fray Luis, pero es preciso definir el contenido y el alcance de su imitación e influencia, ya que no pueden limitarse éstas sólo, como indican algunos editores y comentaristas, a elementos formales y técnicos, y despreciar las coincidencias temáticas y las actitudes y concepciones poéticas. Coincido plenamente con los juicios y certeras opiniones de $\mathrm{H}$. Ettinghausen: "Sin embargo, es importante que tampoco se subestime la influencia temática de Horacio, como ha hecho más de uno de sus editores, con el fin claramente doctrinal de minimizar el peso que tuvo en él el mundo clásico y así exagerar su status de poeta cristiano"16. Para corroborar su tesis cita, entre otros, el autor los testimonios Menéndez Pelayo: "A la oda erótica horaciana, introducida por Garci-Lasso, sucede la flosófico-moral, nunca afeada en fray Luis por el epicureismo"17; el del P. Ángel C. Vega, que concluye así su juicio sobre la influencia de Virgilio y Horacio: "Claro es que todo ello no puede referirse más que a la forma y al colorido poético, pues en cuanto al fondo, ni el uno ni el otro podían satisfacerle plenamente, dado su paganismo crudo y su moral a medias!"18; y dos muy elocuentes del P. Félix García: "Se ha convertido en tópico intolerable la afirmación de que fray Luis es un poeta horaciano, para definir a fray Luis, esta inicial influencia de Horacio no tiene más que un valor técnico o didáctico, lo más imperecedero y estable de la obra poética de fray Luis es lo que menos tiene de Horacio"; "y "fray Luis, sensitivo y arrebatado, elevado y austero, no tiene ningún contacto cordial con Horacio, epicúreo y sensual, ni con su concepto materializado de la vida" ${ }^{19}$.

Quería ahora, para refutar las opiniones anteriores, poner de manifiesto algunas coincidencias, temáticas y formales, entre ambos poetas con el análisis y comentario de una imitación luisisna del venusino: Se trata de la oda El canto y lira mía... imitación clara de la doce del libro segundo de Horacio, que no ha suscitado excesivo interés entre los editores y críticos de fray Luis ${ }^{20}$; tan sólo se le han dedicado anotaciones marginales o algunos comentarios poco afortunados que dan la impresión de que no se ha entendido el contenido y función de este poema ni el de su modelo horaciano.

Las causas de este fenómeno pueden deberse a que la oda no aparece en algunos manuscritos - aunque hoy nadie duda de su autenticidad -, o al nivel literario y poético de la imitación, no precisamente de las más logradas del

\footnotetext{
${ }^{16}$ Ettinghausen, H., op. cit., p. 244.

${ }^{17}$ Menéndez Pelayo, M., op. cit., II, p. 29.

${ }^{18}$ Vega, A. C., Poesías de fray Luis de León. Edición crítica, Madrid 1955, p. 68.

${ }^{19}$ García, F., Obras completas castellanas de fray Luis de León, Madrid 1991, p. 1427 y 1406, respectivamente.

20 "Una de las menos estudiadas", dice C. Cuevas, Fray Luis de León. Poesías completas, Madrid 2001, p. 279.
} 
maestro salmantino, en mi opinión, al menos; opinión que comparte, aunque tal vez por motivos distintos, el Padre Angel C. Vega, que la glosa con las siguientes palabras: "Es auténtica sin ningún género de duda, aunque un poco floja, y, al final, con añadiduras de marcado tono erótico, que el autor rechazó en los últimos días, como indigna de figurar en su colección" ${ }^{21}$. Las "añadiduras" finales figuran en el modelo horaciano, y sólo una interpretación errónea pudo creer y hacer creer que aludían a los amores y pasiones de Grial por la "ilustre Nise". Tal vez esta lectura equivocada y tan distorsionada pudo impulsar a fray Luis a distanciarse de la oda y a suprimirla en su última colección ${ }^{22}$; esta sería la causa de que no aparezca en algunos manuscritos.

Un juicio y una opinión más favorable merece esta imitación al Padre J. Llobera, que la prologa con estas palabras: "Nótese en toda esta oda con qué arte el poeta escanciador sabe trasegar el vino añejo en vasijas nuevas" 23 .

Pienso que en otros poemas la inspiración poética y la musa luisiana alcanzan cotas mucho más elevadas. No es, con todo, el objetivo de esta disquisición filológica valorar los méritos o deméritos literarios de esta imitación, sino exponer y mostrar el sentido y la función que ambos poemas desempeñan en la teoría poética de los dos autores. Una lectura de las odas nos ayudará en esta exposición ${ }^{24}$.

La imitación es diáfana y afecta tanto al contenido como a la estructura del poema, con una adaptación de los hechos romanos a las realidades históricas de la España del momento - obsérvese la alusión a la batalla de Lepanto que nos permite datar, con bastante exactitud, el poema luisiano entre octubre de 1571 y marzo de 1572 , momento en que el poeta es encarcelado ${ }^{25}$-; este dato nos parece muy interesante, porque es probablemente el último poema en el que fray Luis trata del amor humano, curiosamente en los meses anteriores al proceso inquisitorial que acabó con él en la cárcel.

En la primera parte, ambos poetas exponen el contenido de la épica con dos procedimientos diferentes, primero como impropio de su lira y a continuación, como objeto de la poesía de sus dos interlocutores, Mecenas y Grial, respectivamente. Los temas de la épica son las gestas y acciones bélicas famosas de los romanos e hispanos. En el poema horaciano se alude también a la épica mitológica y heroica, que fray Luis sustituye por las glorias del Cid.

${ }^{21}$ Vega, A. C., op. cit., p. 564 .

${ }^{22}$ Ibid., p. 565: "No es fácil averiguar quién sea esta Nise, cuya coquetería pinta aquí con tan vivos colores fray Luis, y que aparece como amante de Grial, que fué eclesiástico y canónigo en Zaragoza y Calahorra. Fray Luis de León suprimió esta imitación - tal vez por demasiado erótica e insinuante - en su última colección poética. El inconveniente de esta imitación no está en que sea traducción del Nolis de Horacio, sino en referirla y aplicarla a Grial. En una revisión destinada a la imprenta esta imitación no debía, no podía figurar sin rubor y desdoro del poeta y del canónigo. Su supresión está justificada suficientemente, aunque sea un juguete literario, y esté fuera de la más leve sospecha de impureza la vida ejemplar de uno y otro".

${ }^{23}$ P. José Llobera, S. J., Obras poéticas del Maestro Fray Luis de León, Cuenca 1932, p. 483.

${ }^{24}$ En el apéndice se reproducen tanto la oda horaciana como la imitación de fray Luis.

${ }^{25}$ Vega, A. C., op. cit., p. 564; Lázaro Carreter, F. “Imitación y diseño en la Oda a Juan Grial”, Academia Literaria Renacentista. I Fray Luis, Salamanca 1981, p. 195. 
En la segunda parte, se define el contenido de la lírica, antitético con el de la épica, que se identifica con la descripción del sentimiento amoroso y de la belleza y encantos de Licimnia y Nise, respectivamente. Terminan ambos poemas con interrogaciones retóricas, con las que se pretende convencer a los interlocutores, teóricamente partidarios del canto épico, de la superioridad y mayor interés de la poesía lírica y de sus temas.

Ya hemos visto que el P.A. Vega habla despectivamente de las "añadiduras" que, realmente, como se desprende de la lectura de Horacio, figuran en el original. También a prestigiosos críticos horacianos ha sorprendido la segunda parte del poema por su inusual sensualidad y porque parece atentar contra el lema horaciano sit simplex dumtaxat et unum, ya que combina la recusatio con la descripción erótica de la amada ${ }^{26}$.

También le viene impuesto por el modelo a fray Luis que en la segunda parte se canten los amores del interlocutor - en este caso los de Grial - y los encantos de su amada, ya que Horacio atribuye a Mecenas los amores y seducciones de Licimnia - piensan los comentaristas que tras Licimnia se esconde Terentia, esposa de Mecenas; ambos nombres poseen idéntica estructura métrica, según la costumbre de los poetas romanos de cambiar el nombre de sus amantes ${ }^{27}$. No hay, por tanto, ninguna razón para pensar que fray Luis tratara de insinuar la existencia de una amante de Grial, ni que la ilustre Nise turbara la actividad del docto canónigo calagurritano - la lectura de la traducción lusiana de la Oda a Pirra hubiera descubierto que también allí se utiliza el nombre de Nise sin que en este caso hubiera posibilidad de confundir al joven adolescente con Grial.

Pese a que la imitación luisiana es ligeramente más breve que el original, hay, con todo, en ella un elemento importante que no figura de forma explícita en el modelo. Mientras Horacio invita a Mecenas a que redacte las gestas romanas sólo en prosa, tuque pedestribus dices historiis proelia Caesaris, fray Luis propone a Grial que escriba "con heroico verso" o "con más libre pluma”, probablemente la soluta oratio de Cicerón o Quintiliano; con la primera expresión se le invita a redactar un poema épico - no es necesario recordar que el verso heroico es el hexámetro, el verso de la epopeya -, invitación que no figura en la oda horaciana, que se limita a pedir a Mecenas que escriba obras históricas en prosa. Muestra el maestro salmantino haber entendido claramente el modelo y conocer las restantes recusationes horacianas en las que de forma palmaria se rechaza el poema épico y se invita al interlocutor a cultivarlo.

${ }^{26}$ G. Williams, The Nature of Roman Poetry, Oxford 1970, p. 64-65: “... ending with a stanza of unusually frank sensuality. The poem itself is made up of two elements: the recusatio and the erotic description of a loved girl". E. Fraenkel, Horace, Oxford 1957, p. 219: "this is one of the cases in wich Horace falls short of his own maxim, sit simplex dumtaxat et unum. The ode is both artificial and overladen". Respetando los criterios de G. Williams y E. Frankel, nos parece que la oda es unitaria y que los versos finales son parte esencial del poema y cumplen la finalidad de convencer al interlocutor de la supremacía de la lírica.

${ }^{27}$ Catulo a Clodia la llama Lesbia; Tícidas a Metela, Perilla; Propercio a Hostia, Cyntia; Tibulo a Plania, Delia; todas designaciones conservan el esquema métrico del nombre de la amante real. 


\section{Poemas programáticos}

La oda horaciana II, 12 es una recusatio - forma poética convencional, cultivada por el venusino en más de una ocasión ${ }^{28}$ - en la que se rechaza, "se recusa”, una invitación a escribir poemas épicos. Las discrepancias, sin embargo, surgen a la hora de interpretar el valor y el sentido de las recusationes ${ }^{29}$. No se trata de poemas escritos únicamente con el objetivo concreto de rechazar una invitación real para redactar epopeyas y cantar las acciones gloriosas de la patria, sino de aprovechar la forma y la estructura de una composición tradicional para exponer las diferencias entre la poesía épica y la lírica, para definir con precisión los temas y contenidos de ésta última y para manifestar la predilección del poeta por el género lírico. Se trata de poemas programáticos de crítica literaria y poética. La invitación, real o ficticia, es un pretexto para redactar la oda.

También pensamos nosotros que la oda de fray Luis tiene un carácter programático, ya que el poeta muestra su simpatía por la lírica y rechaza los cantos épicos, mientras invita a su amigo Grial a que los cultive él mismo. También, unos meses o unos años después, se dirigirá otra vez a Grial para pedirle que cultive los estudios y se dedique al nuevo estilo:

Escribe lo que Febo

Te dicta y favorable, que no antiguo

Iguala y pasa el nuevo

Estilo; y, caro amigo,

No esperes que yo podré atener contigo ...

Suscribo plenamente las palabras de F. Lázaro en un brillante y erudito articulo: "Ambas odas, dirigidas al mismo amigo - Juan de Grial -, deponen sobre la índole literaria que tuvieron sus relaciones; en la primera, lo anima a ensayar tonos épicos; en la que nos ocupa, le pide que continúe escribiendo en el "nuevo estilo" 30.

Se nos podrá decir que en el siglo XVI español no tiene sentido la polémica épica/lírica, pero no debemos olvidar la vigencia de la poética clásica en el Renacimiento y las nuevas orientaciones de la poesía neolatina. Muy oportuno nos parece el acertado análisis de ésta última entre 1544 y 1590 de J. Alcina: "Nos encontramos también con una liberación en los temas y en las formas. Aparece la poesía erótica y desaparecen los intentos de grandes poemas épicos cristianos. La poesía religiosa se fragmenta, prefiere las composiciones breves, más intimas, de lectura solitaria, como si la fragmentación

${ }^{28}$ Las recusationes más importantes y significativas, además de en este poema, se hallan en carm. I, 9; IV, 2; IV, 15; serm. II, 1, 12; epist. II, 1, 250 ss.

${ }^{29}$ No es el momento de analizar y estudiar las recusationes, sobre las que hay una densa bibliografía y de las que se han ocupado la mayoría de los comentaristas horacianos. Una exposición breve y sucinta puede verse en Hinojo, G., Recusationes...?, Noua Tellus 3, 1985, 75-69.

${ }^{30}$ Lázato Carreter, F., "Imitación compuesta y diseño retórico en la oda a Juan de Grial", Academia Literaria Renacentista. I Fray Luis, Salamanca 1981, p. 196. 
de la cristiandad les hubiera hecho perder la confianza en la identificación colectiva del canto épico" ${ }^{31}$.

Aprovechando al máximo su modelo horaciano, fray Luis nos define el género de su poesía y nos muestra su predilección por la lírica, digna de ser cultivada tanto por la riqueza y dulzura de sus temas, como por la belleza y elegancia de sus metros. Una muestra de esta belleza y elegancia son las brillantes y atinadas traducciones del poema horaciano del propio fray Luis de León .

\section{La presencia del interlocutor: Grial}

La presencia del interlocutor, en este caso Grial, viene sugerida al poeta por el propio modelo. El interlocutor es un recurso formal ${ }^{32}$ de la mayoría de las odas horacianas - y no sólo de ésta que imita fray Luis -, cuya función, no siempre suficientemente destacada, es esencial para comprender la organización y estructura de estos poemas del venusino. También en las odas luisianas desempeña un papel importante, como certeramente ha señalado el Profesor E. Alarcos ${ }^{33}$, y por ello le vamos a dedicar un breve comentario.

El interlocutor es una convención formal, probablemente heredada de los modelos griegos ${ }^{34}$, en torno al cual se estructuran las odas, que confiere a éstas una situación de diálogo o coloquio.Puede ser un protector (Mecenas, Augusto), un amigo (Tibulo, Sextio), un dios (Venus, Mercurio), una mujer (Lidia, Lyce), un elemento natural (la nave, la fuente de Bandusia, la lira del poeta), un ser desconocido (un avaro, un siervo), etc. Si repasamos los interlocutores de Horacio y los de fray Luis, encontraremos notables coincidencias.

No debe confundirse el interlocutor con la persona a la que se dedica el poema, aunque con frecuencia coincidan. El interlocutor aparece siempre en el interior del poema, en vocativo, y es objeto de apelaciones, interrogaciones, ruegos, imprecaciones por parte del poeta. Podríamos llamarlo también 'destinatario interno', para distinguirlo de la persona a la que se dedica el poema, que no tiene necesariamente que aparecer en el interior del mismo.

$\mathrm{La}$ presencia del interlocutor confiere a muchas odas un tono y un carácter impresivo, conativo, que ha sido malinterpretado. Algunos críticos y comentaristas piensan que las odas de Horacio son el resultado de un objetivo

${ }^{31}$ J. Alcina, "La poesía latina del humanismo español: un esbozo", Los humanistas españoles y el humanismo europeo, Murcia 1990, p. 22. (La cursiva del texto es nuestra).

${ }^{32}$ Un estudio completo de las función y significado del interlocutor puede verse en nuestro estudio: "El interlocutor ficticio: de Horacio a Luis de León", Actas del Bimilenario Horacio, Salamanca 1994, pp. 404-413.

${ }^{33}$ E. Alarcos, "La oda a Grial de Luis de León”, Homenaje a José Manuel Blecua ofrecido por sus discípulos, colegas y amigos, Madrid 1983, p. 59: "En veintiuna de las veintitrés composiciones sin discusión auténticas del maestro, éste se dirige a alguien, a un interlocutor conocido”.

${ }^{34}$ Algunos piensan que el interlocutor es un elemento derivado de la poesía dramática antigua, mientras que otros creen que se trata de un recurso formal del poeta para justificar el acto de la comunicación y para evitar las críticas por una extroversión innecesaria y superflua. 
práctico concreto y que en ellas está ausente toda comunicación o expresión subjetiva. Ello ha ocasionado numerosas censuras sobre el escaso o nulo lirismo de la poesía horaciana.

Sin embargo, como acertadamente puntualizó el prestigioso R. Heinze ${ }^{35}$, la ficción, incluida la del interlocutor, es un componente esencial de la oda horaciana. Por la ficción se introducen la imaginación y el lirismo, sólo que éste no se entiende de forma personalista, intimista o autobiográfica ${ }^{36}$. El poema parece una comunicación real, pero realmente es una comunicación fingida. E1 Grial de la oda no es el biográfico, sino un interlocutor poético. Caen por tierra definitivamente las opiniones de los que afirman que se habla en el poema de los amores del amigo del poeta.

Pensamos, por tanto, que se equivocan los que interpretan las odas como una invitación y una comunicación real a un destinatario concreto y los que las privan de lirismo. En primer lugar, porque hay algunas odas, no muchas, en las que no aparece el interlocutor y pueden considerarse verdaderos monólogos; en segundo, porque la presencia de elementos conativos y persuasivos no anula la manifestación de los juicios y sentimientos del poeta; y en tercero, porque la presencia del interlocutor no sólo no impide, sino que favorece la libre expresión, y ayuda, por contraste, a definir y precisar las opiniones y vivencias del poeta. Hemos intentado mostrar también como en el poema que fray Luis imita, aunque tuviera como objetivo rechazar la invitación de Mecenas -cuya existencia habría que probar -, el poeta no deja de mostrarnos su personal visión sobre la lírica y la épica ni nos priva de la descripción de los amores y encantos de Licimnia.

Nos parecen mucho más atinados los juicios del Profesor Alarcos que, aunque aplicados sólo a fray Luis, consideramos válidos también para Horacio: "Se trata, pues, de una poesía esencialmente comunicativa, que apela siempre a un tú, más o menos explícito, a quien quiere hacer partícipe de sus preocupaciones"37.

En el poema que nos ocupa, el interlocutor es un elemento utilizado para dar a la oda una forma epistolar, muy adecuada para sugerir el propósito práctico de contestar a las invitaciones, reales o ficticias, de Mecenas y de Grial. Pero sirve, además, para organizar la estructura antitética. La oposición épica/lírica, esencial en el poema, se manifiesta por la antítesis entre la lira de Horacio y fray Luis y el canto épico de Mecenas y Grial. La antítesis sirve para enriquecer e intensificar el contenido de ambas odas, ya que la lírica se define positivamente por su contenido y sus temas, y, negativamente, por ser opuesta y contraria a la épica. La antítesis se refuerza por anáforas, paralelismos y posiciones equivalentes en la responsión estrófica, pero estos mecanismos se intensifican por la oposición del poeta y del interlocutor.

${ }^{35}$ R. Heinze, "Die horazische Ode", NJ 51 (1923) pp. 161 ss.

${ }^{36}$ Un análisis riguroso de la teoría de Heinze y un estudio completo de la ficción en la lírica horaciana se halla en el trabajo de C. Fernández Corte, "Del sentido en que se ha aplicado a Catulo y Horacio el término de poetas líricos y de la sinceridad como criterio valorativo de sus poemas", Veleia 7 (1990) 317-336.

${ }^{37}$ E. Alarcos, op. cit., p. 59. 
También la presencia de este último concede al poeta la posibilidad de introducir elementos impresivos y conativos para persuadir, tanto a los interlocutores como a los lectores, de la superioridad de la lírica, uno de los objetivos del poema. Muy relacionados con la persuasión están los recursos retóricos - aquí las interrogaciones finales -, relativamente frecuentes tanto en la lírica horaciana como en la luisiana.

Finalmente, la presencia del interlocutor ha permitido a ambos poetas describirnos la pasión y los sentimientos amorosos sin tener que darles un sentido personal ni autobiográfico. En la traducción de las dos últimas estrofas, "las añadiduras de marcado tono erótico, que el autor rechazó en los últimos días, como indigna de figurar en su colección”, fray Luis muestra su sensibilidad y su finura para captar el sentido de la estrofa horaciana y para describir con encanto la belleza del sentimiento amoroso ${ }^{38}$. No sabemos si se avergonzó de ellas o le obligaron a ello, porque tras invitar a Grial a escribir lo que Febo le dicte, lamenta no poder atener con él:

que yo de un torbellino

traidor acometido y derrocado

del medio del camino

al hondo, el plectro amado

y del vuelo las alas he quebrado.

Probablemente el miedo a la Inquisición y la autocensura cortaran la inspiración del poeta castellano y le impidieron en su poesía posterior original cantar los encantos y las delicias del amor humano que de forma tan sutil y elegante nos ofrece en esta oda, recreación de la famosa recusatio horaciana.

\section{Epílogo}

Pensamos, como conclusión, que fray Luis captó perfectamente el sentido y valor del poema del venusino, y con esta imitación pretendía de forma explícita hacer suyo el código poético y literario de Horacio, especialmente su predilección por la poesía lírica, mucho más humana y atractiva que la épica, pese a la doctrina de la tradición anterior, y mucho más acorde también con el ideario y el temperamento de ambos poetas.

En su producción poética original explotará con éxito el maestro salmantino la riqueza y diversidad temática de la lírica horaciana - poesía religiosa y heroica, rústica y campestre, epinicios, himnos, odas literarias, etc. ${ }^{39}$ - y sabrá adaptarla a las exigencias y gustos de su época. También sabrá utilizar con acierto diversos elementos formales horacianos como la presencia del

${ }^{38}$ Un análisis espléndido y muy bien documentado sobre la poesía de fray Luis y el sentimiento amoroso puede verse en el brillante artículo ya citado ("Fray Luis..., op. cit., pp. 1620) de el maestro recientemente desaparecido, Fernando Lázaro, ilustre catador y comentarista de la poesía luisiana, de quien todo lector de fray Luis debe sentirse deudor.

${ }^{39}$ En la clasificación temática de las odas que establece O. Macrí, Fray Luis de León. Poesías, Nueva edición revisada, Barcelona 1982, p. 46, se hallan la mayoría de los temas del venusino. 
interlocutor, la responsión estrófica, la estructura de las odas, los paralelismos, las antítesis, las figuras fonoestilísticas, los encabalgamientos, etc.

Como el venusino, podría nuestro poeta enorgullecerse de haber sido el primero en adaptar las formas y los ritmos latinos a la lengua castellana y de haber concluido una obra imperecedera (aere perennius) que no lograrán destruir ni el inexorable paso del tiempo ni los cambios de escuelas y doctrinas poéticas.

\section{Bibliografía}

Agrait, G., El 'beatus ille’ en la poesía lírica del Siglo de Oro, México 1971.

Alarcos, E., "La oda a Grial de Luis de León”, Homenaje a José Manuel Blecua ofrecido por sus discipulos, colegas y amigos, Madrid 1983, 59-72.

Alcina, J. F., Fray Luis de León. Poesía, Madrid 1989.

Alonso, D., "Fray Luis de León y la poesía renacentista”, Obras Completas, II, Madrid 1973, 769-788.

B lecua, J. M., Fray Luis de León. Poesía completa, Madrid 1990.

Blecua Perdices, A. "El entorno poético de fray Luis", Academia Literaria Renacentista. I Fray Luis, Salamanca 1981, 77-99.

Bocchetta, V., Horacio en Villegas y en fray Luis de León, Madrid 1970.

Conde, J. L., "Horacio en Pessoa: la muerte de una tradición de la lírica occidental", Bimilenario de Horacio, Salamanca 1994, 193-205.

Cristobal, V., "Horacio y fray Luis", Horacio, el poeta y el hombre, Santiago de Compostela 1994, 163-189.

Cuevas, C., Fray Luis de León. Poesías completas, Madrid 2001.

Davies, G. A., "Notes on some classical sources for Garcilaso and Luis de León”, Hispanic Review 32, 1964, 202-216.

Echave-Susaeta, J. de, "Presencia de Horacio en nuestras letras", Actas del II Congreso Español de Estudios Clásicos, Madrid-Barcelona 1971, 475489.

Ettinghausen, H., "Horacianismo vs. neoestoicismo en la poesía de fray Luis de León", Fray Luis de León: Historia, humanismo y letras, Salamanca 1996, 241-253.

Gallardo, C., "Las resonancias de Horacio en fray Luis de Léón", Siglo de Oro, 11, 1992, 71-85.

García, F. Obras completas castellanas de fray Luis de León, Madrid 1991.

García Fuentes, M. C., "Pervivencias horacianas en Jorge Manrique", Cuadernos de Filología Clásica 9, 1975, 201-211. 
González de Escandón, B., Los temas del 'carpe diem' y la brevedad de la rosa en la poesía española, Barcelona 1938.

González Rolán, T., "Horacio en el Medievo hispánico", Horacio, el poeta y el hombre, Santiago de Compostela 1994, 141-161.

Hinojo Andrés, G., "Recusationes...?” Nova Tellus 3, 1985, 245- 255.

"El interlocutor ficticio, de Horacio a Luis de León”, Bimilenario de Horacio, Salamanca 1994, 405-13.

—_ "La poética horaciana en Luis de León: La recusatio, Studia philologica in bonorem O. García de la Fuente, Madrid 1994, 531-43.

Lapesa, R., La obra literaria del Marqués de Santillana, Madrid 1957.

Lázaro Carreter, F., "Imitación compuesta y diseño retórico en la Oda a Juan de Grial", Academia Literaria Renacentista. I Fray Luis, Salamanca 1981, 193-223.

___ “Fray Luis de León y la clasicidad”, Fray Luis de León: Historia, humanismo $y$ letras, Salamanca 1996, 15-30.

LidA, M. R., La tradición clásica en España, Barcelona 1975 (esp. pgs. 252-276).

Llobera, J., “La formación horaciana del M. fray Luis de León”, Razón y Fe 86, 1929, 49-62.

Luis de León. Obras poéticas, Cuenca 1931-1933.

López Báez, M. R., Horacio en España, siglos XVI-XVII, Barcelona 1975.

Macrí, O., Fray Luis de León. Poesías, Nueva edición revisada, Barcelona 1982.

Menéndez Pelayo, M., Horacio en España, Madrid 1885 (recogido en su Bibliografía hispano-latina clásica, Santander 1951, VI).

Quint, M. B., Untersuchungen zur mittelalterlichen Horaz-Rezeption, Frankfurt am Main 1988.

Riba, C., "Horaci en les literatures ibèriques”, La Revista, 1935.

Rico, F., "Tradición y contexto en la poesía de fray Luis de León”, Academia Literaria Renacentista. I Fray Luis, Salamanca 1981, 245-248.

Rivers, E., "The Horatian Epistle and its Introduction into Spanish Literature", Hispanic Review 22, 1954, 175-194.

—_ “Fray Luis de León: tradición e imitación”, Edad de Oro 4, 1985, 107-115.

Rodríguez, C., "Fray Luis de León, ¿'horaciano o virgiliano?", La Ciudad de Dios 154, 1942, 5-21.

Rubio, F., "Los fondos horacianos de la Biblioteca del Escorial”, La Ciudad de Dios 152, 1936, 385-399. 
Horácio e a sua perenidade

Vega, A. C., Fray Luis de León. Poesias, Madrid 1955.

Zorita, C., "Fray Luis, traductor de Horacio", Fray Luis de León. Aproximaciones a su vida y su obra, Santander 1989, 281-310. 